\title{
Apollinarius und seine Folgen
}

\author{
Hrsg. v. Silke-Petra Bergjan, Benjamin Gleede u. Martin Heimgartner
}

Apollinarius und seine Folgen

Herausgegeben von SILKE-PETRA BERGJAN, BENJAMIN GLEEDE und MARTIN HEIMGARTNER

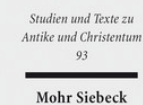

Mohr Siebeck

2015. XII, 309 Seiten. STAC 93

SBN 978-3-16-153588-8

DOI 10.1628/978-3-16-153588-8

eBook PDF $89,00 €$

ISBN 978-3-16-153587-1

fadengeheftete Broschur 89,00€

Apollinarius war auf der einen Seite ein Theologe und Bischof, dem man hohen Respekt entgegenbrachte, poetisch begabt, hochgebildet und Zeitgenosse von Basilius von Caesarea, Nizäner und doch auf der anderen Seite der Urheber der woh wirkungsvollsten Häresie der Antike, die seit 383 in kaiserlichen Edikten verboten wurde und deren Anhänger doch 428 wieder in die Grosskirche aufgenommen wurden.

Dieser Band vereint Aufsätze zu ganz verschiedenen Aspekten der Person des Apollinarius und seiner Schüler. Gefragt wird nach einem Apollinarius, der nicht von Vorneherein mit dem Häretiker identifiziert ist, zu dem er in den 70er Jahren wurde. Die frühen Zeugnisse zeigen, wie Apollinarius eingebunden in Entwicklungen ist, die in den 360er Jahren erst einsetzen, wieviel inn in dieser Zeit mit Diodor oder Gregor von Nazianz verband und wie sehr sein Denken durch die Stadt Antiochien und die Begegnungen dort geprägt ist.

Die Autoren der Beiträge untersuchen auch, welche Bedeutung die apollinaristischen Gruppen seit dem 5. Jahrhundert hatten Die Überlieferung der anti-apollinaristischen Schriften im Rahmen der Athanasius-Corpora, aber auch bisher unbekannte Testimonien werden vorgestellt. Die apollinaristischen Gruppen und ihre Bedeutung, neue, bisher unbekannte Testimonien und das Apollinarius Bild in byzantinischen Quellen werden vorgestellt.

Inhaltsübersicht

I. Der frühe Appolinarius: Nachrichten aus der Zeit um und vor 360

Susanna Elm: Apollinarius of Laodicea and Gregory of Nazianzus: The Early Years - Kelley McCarthy Spoerl: The Circumstances of Apollinarius's Election in Laodicea - Volker Henning Drecoll: Apollinarius, Ad lovianum : Analyse und Bedeutung für die Apollinariuschronologie - Markus Vinzent: Pseudo-Athanasius, Oratio contra Arianos IV: Apollinarius' Earliest Extant Work

\section{Zur Theologie des Apollinarius}

Hanns Christof Brennecke: »Apollinaristischer Arianismus« oder »arianischer Apollinarismus«: ein dogmengeschichtliches Konstrukt? - Johannes Zachhuber: Derivative Genera in Apollinarius of Laodicea: Some Remarks on the Philosophical

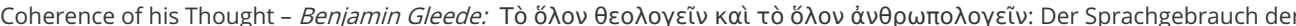
Schrift als Wurzel apollinarischer Christologie - Ekkehard Mühlenberg: Theologie und Frömmigkeit bei den Apollinaristen

III. Fragmente des Apollinarius und Schriften seiner Gegner in ihren Überlieferungskontexten

Uta Heil: Athanasius, Apollinarius und der pseudathanasianische Sermo contra omnes haereses - Alessandro Capone: Pseudo-Athanasius: De incarnatione contra Apollinarium : Einleitende Bemerkungen zur handschriftlichen Überlieferung Martin Heimgartner: Neue Fragmente Diodors von Tarsus aus den Schriften »Gegen Apollinarius«, »Gegen die Manichäer« und »Über den heiligen Geist« - Karin Metzler: Segen für die Stämme Israels. Neue Testimonien für die Auslegung des Apollinarius von Gen 49 und Dtn 33 (aus CPG 3680)

\section{Apollinarius in der Wahrnehmung der späteren Jahrhunderte}

Silke-Petra Bergjan: Theodoret von Cyrus, Apollinarius und die Apollinaristen in Antiochien - Theresia Hainthaler: Die apollinaristischen Fälschungen und die christologischen Debatten des 5. und 6. Jahrhunderts. Einige Beobachtungen - Patrick Andrist: The Two Faces of Apollinarius: A Glimpse into the Complex Reception of an Uncommon Heretic in Byzantium

Silke-Petra Bergjan Born 1962; 1992 Dr.theol. Ludwig-Maximilians-University in Munich; 1999 Habilitation in Church History at the Humboldt University in Berlin; since 2000 Professor of Church History (from the Early Church to the Time of Reformation) at the University of Zurich.

Benjamin Gleede ist Wissenschaftlicher Mitarbeiter (SNF Projekt) am Lehrstuhl für Kirchen und Theologiegeschichte an der Theologischen Fakultät der Universität Zürich.

Martin Heimgartner ist apl. Professor für Kirchengeschichte an der Martin-Luther-Universität Halle-Wittenberg und Wissenschaftlicher Mitarbeiter (SNF Projekt) am Lehrstuhl für Kirchen- und Theologiegeschichte an der Theologischen Fakultät der Universität Zürich.

Jetzt bestellen:

https://mohrsiebeck.com/buch/apollinarius-und-seine-folgen-9783161535888?no_cache=1

order@mohrsiebeck.com

Telefon: +49 (0)7071-923-17

Telefax: +49 (0)7071-51104 